\title{
Effects of the Electrode Wettability on the Deep Discharge Capacity of $\mathrm{Li}-\mathrm{O}_{2}$ Batteries
}

\author{
Fangzhou Wang and Xianglin $\mathrm{Li}^{*}$ (1) \\ Department of Mechanical Engineering, University of Kansas, Lawrence, Kansas 66045, United States \\ Supporting Information
}

ABSTRACT: The wettability of customized $\mathrm{Li}-\mathrm{O}_{2}$ battery electrodes is altered by mixing acetylene black carbon particles with various binders. The wettability of the electrode can be characterized by the static contact angles between the electrode surface and nonaqueous electrolyte, which is $1 \mathrm{M}$ bis(trifluoromethane)sulfonimide lithium salt (LiTFSI) dissolved in tetraethylene glycol dimethyl ether, and the double-layer capacitance measured by the cyclic voltammetry. Results show that electrodes containing poly(vinylidene difluoride) (PVDF) binder are lyophilic and increasing the fraction of poly(tetrafluoroethylene) (PTFE) increases the lyophobicity of electrodes. $\mathrm{Li}-\mathrm{O}_{2}$ batteries are discharged at $0.1 \mathrm{~mA} / \mathrm{cm}^{2}$ with the cut-off voltage of $2.0 \mathrm{~V}$. The discharge capacity of the electrode with $15 \%$ PVDF $\left(36.5^{\circ}\right)$ carbon coatings is $1665.8 \mathrm{mAh} / \mathrm{g}$, whereas the customized electrode with $15 \%$ PTFE $\left(128.4^{\circ}\right)$ carbon coatings obtains the

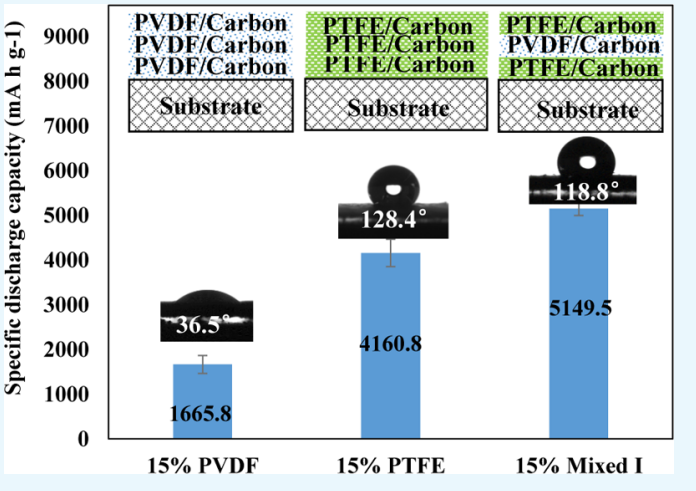
discharge capacity of $4160.8 \mathrm{mAh} / \mathrm{g}$. However, the discharge capacity decreases to 3109.5 and $2822.9 \mathrm{mAh} / \mathrm{g}$ as the PTFE content further increases to $25 \%\left(135.5^{\circ}\right)$ and $35 \%\left(138.5^{\circ}\right)$, respectively. The electrode composed of two lyophobic carbon coatings on top and bottom and one lyophilic carbon coating in the middle has the static contact angle of $118.8^{\circ}$ and acquires the highest specific discharge capacity of $5149.5 \mathrm{mAh} / \mathrm{g}$.

\section{INTRODUCTION}

Greenhouse gas emissions from the production and consumption of fossil fuels have resulted in global climate change, acid rain, as well as other environmental consequences, which attract growing concerns from the world. Thus, renewable energy is emerging and thriving globally to replace the fossil fuels. However, the lower energy density and intermittency of renewable energy, such as solar energy and wind energy, limit their commercialization. ${ }^{1}$ Currently, the rechargeable battery is considered as one of the compromising technologies to efficiently store renewable energy. Among rechargeable batteries, the Li-ion battery has achieved a great success and has been widely applied in many devices and instruments, including mobile phones and electrical vehicles. ${ }^{2}$ The practical specific energy of the Li-ion battery $(\sim 200 \mathrm{Wh} / \mathrm{kg})$, however, has already approached the theoretical specific energy $(\sim 600$ $\mathrm{Wh} / \mathrm{kg})^{3}$

The Li-air battery using $\mathrm{O}_{2}$ from the atmosphere displays a much higher theoretical energy density $(\sim 11000 \mathrm{Wh} / \mathrm{kg}$ based on $\mathrm{Li}$ anode) than other rechargeable batteries. ${ }^{4}$ However, many obstacles, such as the low discharge-charge current rate, low charge discharge energy efficiency, and poor cycle life need to be overcome to commercialize the Li-air battery. ${ }^{5,6}$ Since $\mathrm{CO}_{2}$ and $\mathrm{H}_{2} \mathrm{O}$ in air would react with active components in batteries and deteriorate the performance, most laboratory experiments were conducted under pure $\mathrm{O}_{2}$ environment. ${ }^{7,8}$ Experiments in this study has utilized pure $\mathrm{O}_{2}$ so that the term $\mathrm{Li}-\mathrm{O}_{2}$ battery is presented throughout this paper. Generally, a rechargeable $\mathrm{Li}-\mathrm{O}_{2}$ battery using organic electrolyte consists of a lithium metal anode, a separator saturated with the organic electrolyte, and a porous cathode electrode (typically made from carbon or catalysts). The electrochemical reactions occurring on the anode and cathode as well as the overall reaction are shown below. The reversible cell voltage is $2.96 \mathrm{~V}$.

$$
\begin{aligned}
& \text { anode: } \mathrm{Li} \underset{\text { charge }}{\stackrel{\text { discharge }}{\rightleftarrows}} \mathrm{Li}^{+}+\mathrm{e}^{-} \\
& \text {cathode: } \mathrm{O}_{2}+2 \mathrm{e}^{-}+2 \mathrm{Li}^{+} \underset{\text { charge }}{\stackrel{\text { discharge }}{\rightleftarrows}} \mathrm{Li}_{2} \mathrm{O}_{2}(\mathrm{~s}) \\
& \text { overall: } 2 \mathrm{Li}+\mathrm{O}_{2} \underset{\text { charge }}{\stackrel{\text { discharge }}{\rightleftarrows}} \mathrm{Li}_{2} \mathrm{O}_{2}(\mathrm{~s})
\end{aligned}
$$

During the discharge operation, the Li metal is oxidized at the anode to generate lithium ion that transfers through the separator and reaches the porous cathode. The lithium ion reacts with oxygen from the ambient or gas channels and generates lithium peroxide $\left(\mathrm{Li}_{2} \mathrm{O}_{2}\right)$ at the cathode. The oxygen reduction reaction (ORR) should occur both on triphase boundaries formed by the electrode material, the electrolyte and oxygen, as well as the interface of electrode material and electrolyte. The charging reactions at the anode and cathode

Received: April 25, 2018

Accepted: May 23, 2018

Published: June 4, 2018 
are reversed from discharging reactions in which lithium peroxide is decomposed and oxygen is released at the cathode and lithium metal is deposited at the anode.

The $\mathrm{O}_{2}$ diffusion in the porous cathode is a key factor that determines the discharge capacity of $\mathrm{Li}-\mathrm{O}_{2}$ batteries. ${ }^{10,11}$ Therefore, many studies on $\mathrm{Li}-\mathrm{O}_{2}$ batteries have paid considerable attention to the $\mathrm{O}_{2}$ diffusion in the porous cathode because poor $\mathrm{O}_{2}$ diffusion will reduce the capacity. The $\mathrm{O}_{2}$ diffusion in the porous cathode is related to carbon loading, ${ }^{12}$ pore clogging induced by the deposition of solid lithium peroxide, ${ }^{13-16}$ and the partial pressure of oxygen. ${ }^{17}$ In addition, the wettability between the electrolyte and electrode also significantly affects the performance of $\mathrm{Li}-\mathrm{O}_{2}$ batteries because the $\mathrm{O}_{2}$ diffusion coefficient in air is several orders of magnitude higher than that in the liquid electrolyte. For instance, the $\mathrm{O}_{2}$ diffusion coefficient ${ }^{18}$ in nonaqueous electrolyte calculated by the Stokes-Einstein equation is on the order of $10^{-6}$, whereas the diffusion coefficient is on the order of $10^{-2}$ in air. ${ }^{19}$ The contact angle is often applied to characterize the wetting behavior between the liquid and solid surface. The electrolyte and carbon material in electrode possess different dielectric constants, which affect the wettability of the solid to the liquid. The contact angle of the electrolyte on the surface of carbon electrode increases when the difference of dielectric constant between the electrolyte and carbon electrode is larger. The electrolyte with a larger contact angle is less likely to wet the carbon electrode. $\mathrm{Xu}$ et al. ${ }^{20}$ showed that the wettability affected the $\mathrm{O}_{2}$ diffusion in the porous electrode and thus the discharge and charge capacities. The measured contact angles of $1 \mathrm{M}$ bis(trifluoromethane)sulfonimide lithium salt (LiTFSI) in various nonaqueous solvents and their mixtures on the surface of both carbon and Teflon showed that the discharge capacity was improved when the contact angle increased. For example, the contact angle of $1 \mathrm{M}$ LiTFSI in propylene carbonate (PC)/ethylene carbonate (EC) (1:1 wt) on the surface of carbon was $47^{\circ}$, whereas that of $1 \mathrm{M} \mathrm{LiTFSI} \mathrm{in} \mathrm{PC/}$ dimethoxyethane (DME) (1:1 wt) on the surface of carbon was $5^{\circ}$. The discharge capacity with the PC/EC solvent was 167.5 $\mathrm{mAh} / \mathrm{g}$, whereas the capacity was only $27.4 \mathrm{mAh} / \mathrm{g}$ with the PC/DME solvent. Binders such as poly(vinylidene difluoride) (PVDF) and poly(tetrafluoroethylene) (PTFE) are used to combine different types of small particles together and adjust the wettability of cathode electrode in $\mathrm{Li}-\mathrm{O}_{2}$ batteries. Zhang et $\mathrm{al}^{21}$ investigated the wettability of carbon electrodes using the electrolyte of $1 \mathrm{M} \mathrm{LiPF}_{6}$ in $\mathrm{PC} / \mathrm{EC}$ with a weight ratio of 1:1. The electrode made from Super $\mathrm{P}$ carbon mixed with PTFE (8:2 wt) had the contact angle of $99^{\circ}$, whereas the electrode made from KB 600 carbon mixed with PTFE (8:2 wt) had the contact angle of $56^{\circ}$. The battery with lyophobic electrode obtained a higher discharge capacity $(3175 \mathrm{mAh} / \mathrm{g})$ than the battery with a lyophilic electrode $(798 \mathrm{mAh} / \mathrm{g})$.

On the other hand, strongly lyophobic electrodes may deteriorate the discharge-charge performance. The $\mathrm{Li}-\mathrm{O}_{2}$ battery using lyophobic electrode was researched by Chen et al., $^{22}$ in which the experimental data showed that the specific discharge capacity increased from 1365 to $2365 \mathrm{mAh} / \mathrm{g}$ when the PTFE weight ratio increased from 0 to $30 \%$. However, the electrode composed of 40 wt \% PTFE deteriorated the performance of $\mathrm{Li}-\mathrm{O}_{2}$ battery such that the specific discharge capacity decreased to $2130 \mathrm{mAh} / \mathrm{g}$. The PTFE weight ratio should be optimized because a higher PTFE content will reduce the amounts of triphase boundaries for the electrochemical reactions battery electrode. The contact angles of water on the surface of raw carbon paper and carbon paper with 30 wt \% PTFE were measured to be 136.6 and $148.3^{\circ}$, respectively. It should be noted that the water and liquid electrolytes have very different dielectric constants: the dielectric constant of water is $78.3^{23}$ at $25^{\circ} \mathrm{C}$, whereas that of tetraethylene glycol dimethyl ether (TEGDME) is 7.9. ${ }^{24}$ Therefore, the contact angle measured by water cannot represent the surface wettability between electrode and liquid electrolyte.

Because of the significantly different $\mathrm{O}_{2}$ diffusivity in gas phase and electrolyte phase, electrodes with mixed wettability could create triphase boundaries that facilitate the oxygen transfer through gas phase (nonwetted pores). However, too many nonwetted pores will decrease the ionic conductivity of electrodes. Therefore, this study has conducted a systematic investigation on the effects of wettability of electrodes toward organic electrolyte (including both lyophilicity and lyophobicity) and its effects on the deep discharge capacity of $\mathrm{Li}-\mathrm{O}_{2}$ battery. The wettability of electrode was adjusted by mixing carbon powders with different binders (PTFE and PVDF) at various weight ratios. The stability of binders has been systematically examined $^{25}$ in the presence of commercial $\mathrm{Li}_{2} \mathrm{O}_{2}$, which showed that PVDF was unstable because of the presence of highly electron-withdrawing functional groups and an $\alpha$ or $\beta$ hydrogen atom next to them. The PTFE binder was demonstrated to be stable in the presence of $\mathrm{Li}_{2} \mathrm{O}_{2}$. In addition, the PVDF binder was confirmed to degrade in $\mathrm{Li}-\mathrm{O}_{2}$ batteries. $^{26}$ The products formed in the PVDF degradation was measured by Raman spectroscopy and showed the Raman shifts of $\sim 1123$ and $1525 \mathrm{~cm}^{-1}$. However, the degradation can be prevented by drying the electrode under higher temperature, such as $200{ }^{\circ} \mathrm{C}$. Thus, the stability of PTFE and PVDF binders can be guaranteed in this study if the electrodes are prepared according to the process in Experimental Section. The wettability of various customized electrodes was indicated by the contact angles of $1 \mathrm{M}$ LiTFSI/TEGDME electrolyte on the customized electrode surface as well as the double-layer capacitance, which is proportional to the area of wetted pore surface in the electrode. ${ }^{27}$ After comparing the specific discharge capacities of electrodes with lyophilic and lyophobic carbon coating layers, the electrodes consisting of mixed coating layers were produced and tested to optimize the discharge-charge performance. The study shed light on the criteria to improve the $\mathrm{O}_{2}$ diffusion and increase the specific discharge capacity of $\mathrm{Li}-\mathrm{O}_{2}$ batteries.

\section{RESULTS AND DISCUSSION}

2.1. Initial Deep Discharge. All these customized electrodes are tested by the deep discharge experiments at the current density of $0.1 \mathrm{~mA} / \mathrm{cm}^{2}$. The discharge capacity of raw carbon cloth is negligible $(<100 \mathrm{mAh} / \mathrm{g})$ due to the low specific surface area. Therefore, the reported specific discharge capacity is calculated on the basis of the weight of carbon powders coated on the electrode without considering the weight of raw carbon cloth substrate and binders. The discharge curves with the highest discharge capacity among three repeated experiments of each electrode are shown in Figure 1, and the discharge capacities are compared in Figure 2. The lowest specific discharge capacity of $1665.8 \mathrm{~mA} / \mathrm{h} \mathrm{g}$ is achieved by the electrode with $15 \%$ PVDF carbon coatings. When the PTFE binder is used in the customized electrode, the electrode becomes more lyophobic. The specific discharge capacities of $\mathrm{Li}-\mathrm{O}_{2}$ batteries increase from 3145.8 to $4160.8 \mathrm{mAh} / \mathrm{g}$ when the mass fraction of PTFE binder increases from 5 to $15 \%$ but 


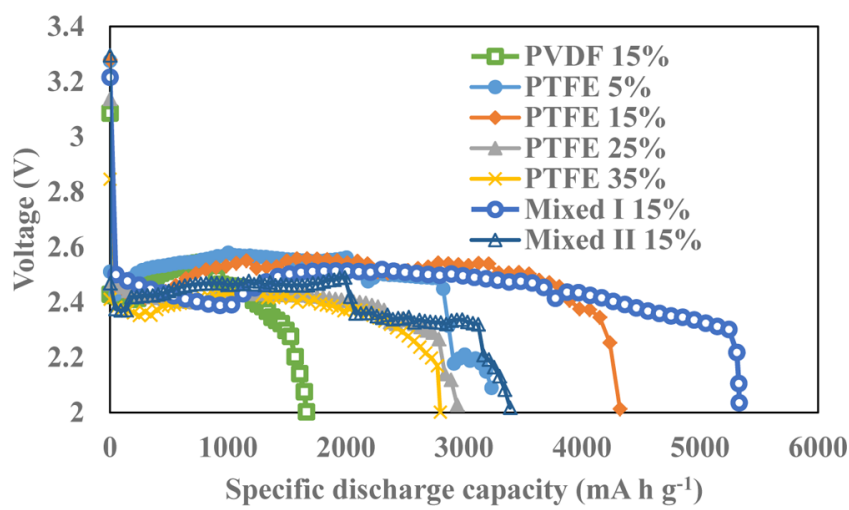

Figure 1. Deep discharge curves of $\mathrm{Li}-\mathrm{O}_{2}$ batteries with customized electrodes.

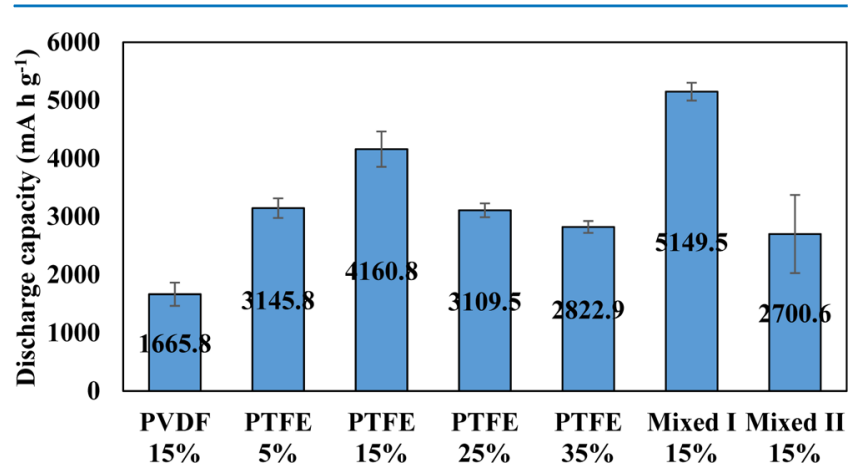

Figure 2. Deep discharge $\mathrm{Li}-\mathrm{O}_{2}$ batteries using customized electrode.

decreases to 3109.5 and $2822.9 \mathrm{mAh} / \mathrm{g}$ when the mass fraction of PTFE binder further increases to 25 and $35 \%$. The significant variation of specific discharge capacity can be attributed to the wettability change. To quantitatively correlate the discharge capacity with the electrode wettability, both the static contact angle and the double-layer capacitance of customized electrodes are measured and exhibited.

2.2. Contact Angle Measurement. The static contact angle between electrolyte and electrode surface is measured to indicate the surface wettability difference among customized electrodes with various contents of PTFE and PVDF binders. Instead of measuring contact angle between a water drop and electrode surface, ${ }^{22}$ the $1 \mathrm{M}$ LiTFSI/TEGDME electrolyte (5 $\mu \mathrm{L}$ per drop) is dropped on the surface of customized electrodes to measure the static contact angle. The measured static contact angles $\left(<90^{\circ}\right.$ for lyophilic surface and $>90^{\circ}$ for lyophobic surface) as well as images of electrolyte drops on electrode surfaces are shown in Figure 3.

The measurement of static contact angle is unsuccessful when the electrolyte drop is dripped on the surface of customized electrode containing 5\% PTFE because the electrolyte droplet quickly spreads into the electrode. It indicates that the surface of 5\% PTFE is lyophilic and is more easily wetted by the electrolyte. When the PTFE content increases from 15 to $35 \%$, the electrode becomes more lyophobic and the static contact angle increases from 128.4 to $138.5^{\circ}$. The mixed I electrode, which consists of one $15 \%$ PVDF coating sandwiched by two $15 \%$ PTFE coatings, displays a slightly lower static contact angle $\left(118.8^{\circ}\right)$ than the electrode with $15 \%$ PTFE. It may be caused by the fact that a small amount of PVDF binder is mixed on the top layer of carbon coating during the fabrication. In addition, the contact angles of

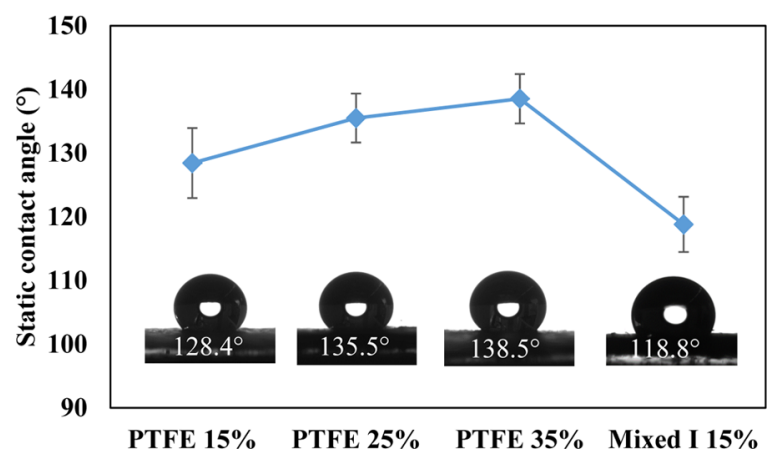

Figure 3. Results of static contact angle measurements on customized electrode surface.

customized electrodes with 15\% PVDF carbon coatings as well as the mixed II electrode consisting of one 15\% PTFE carbon coating sandwiched by two $15 \%$ PVDF carbon coatings are less than $90^{\circ}$ and are unstable.

2.3. Double-Layer Capacitance Measurement. Since static contact angles represent the surface rather than internal wettability of customized electrodes, the double-layer capacitance of customized electrodes is also measured. This study employs an electrochemical approach ${ }^{27}$ to quantify the solidliquid interfacial area and promote the understanding of wettability within customized electrodes. The electric double layer is created on the electrode surface that is wetted by the electrolyte because the customized electrode made of carbon powders is electrically conductive. The double-layer capacitance is related to the wetted interfacial area via the following equation

$$
C=\varepsilon_{\mathrm{r}} \varepsilon_{0} \frac{A_{\mathrm{sl}}}{d}
$$

where $C$ is the capacitance, $\varepsilon_{\mathrm{r}}$ is the relative permittivity of the electrolyte, $\varepsilon_{0}$ is the permittivity of the vacuum, $d$ is the doublelayer thickness, which can be approximated as Debye length, and $A_{\mathrm{sl}}$ represents the wetted pore surface. For an electrolyte with the given composition measured at the room temperature, parameters of $\varepsilon_{\mathrm{r}}, \varepsilon_{0}$, and $d$ can be considered as constants. Therefore, the change of the area of the wetted pore surface is proportional to the variation of the double-layer capacitance.

Figure 4 exhibits the relationship between the volume of added electrolyte and the measured double-layer capacitance. Considering the battery frame shown in Figure 8, the doublelayer capacitance is related to the wetted pore surface in the electrode as well as the wetted area in the current collector. Thus, it is necessary to measure the capacitance when only the

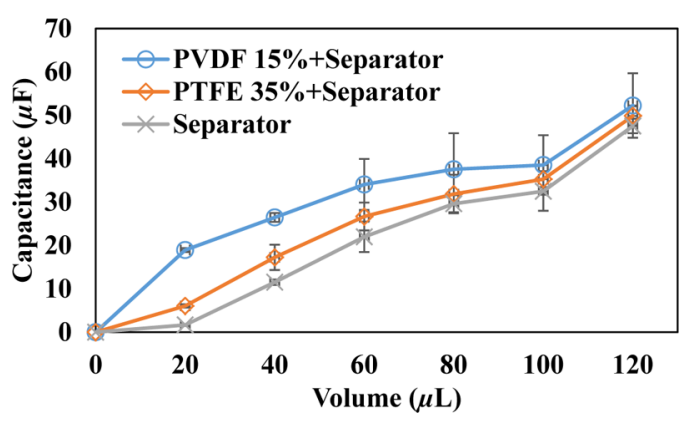

Figure 4. Double-layer capacitance vs volume of electrolyte added on the customized electrode. 
strongly lyophilic separator is inserted in the battery. Generally, as more electrolyte is added, more pore surface is wetted so that the double-layer capacitance increases. The customized electrode containing 15\% PVDF has larger capacitances than that with 35\% PTFE because the former electrode is more lyophilic and more pores are wetted by electrolyte. For example, the capacitance of the electrode with 15\% PVDF was $12.9 \mu \mathrm{F}$ more than that of the electrode with $35 \%$ PTFE at the volume of $20 \mu \mathrm{L}$. The capacitance of 35\%-PTFE electrode combined with the separator is only slightly higher $(<5 \mu \mathrm{F}$ in all volumetric cases) than that of a single separator, as shown in Figure 4. It indicates that most of the electrolyte added into the lyophobic electrode is repelled into the lyophilic separator. The double-layer capacitance increases almost linearly with the amount of added electrolyte when the electrolyte is less than 60 $\mu \mathrm{L}$. As the electrolyte is added, more electrolyte spreads into the separator. Therefore, the wetted surface in the current collector may account for a larger fraction of the double-layer capacitance. The sudden rise in the capacitance after $100 \mu \mathrm{L}$ may be attributed to the fact that electrolyte is squeezed out from the battery frame and the extra double layer is created. Although the compression during battery assembly may partially compensate the capillary pressure within the electrode and cause measuring errors, especially when the electrolyte was more than $60 \mu \mathrm{L}$, the measurement of double-layer capacitance demonstrates the general trend that more pores are wetted by the electrolyte in the lyophilic electrodes.

2.4. Discussion. More lyophobic electrodes facilitate $\mathrm{O}_{2}$ diffusion by creating more gas paths. The improvement of $\mathrm{O}_{2}$ transfer results in a higher specific discharge capacity. However, the specific discharge capacity of the electrode decreases after further increasing the PTFE content to more than $15 \%$. The influences of PTFE content on specific discharge capacity possesses good consistency with the published data. ${ }^{22}$ Further increasing the PTFE content generates more lyophobic pores that reduce the number of triphase boundaries for the ORR reaction and decreases the ionic conductivity. In Figure 5, the

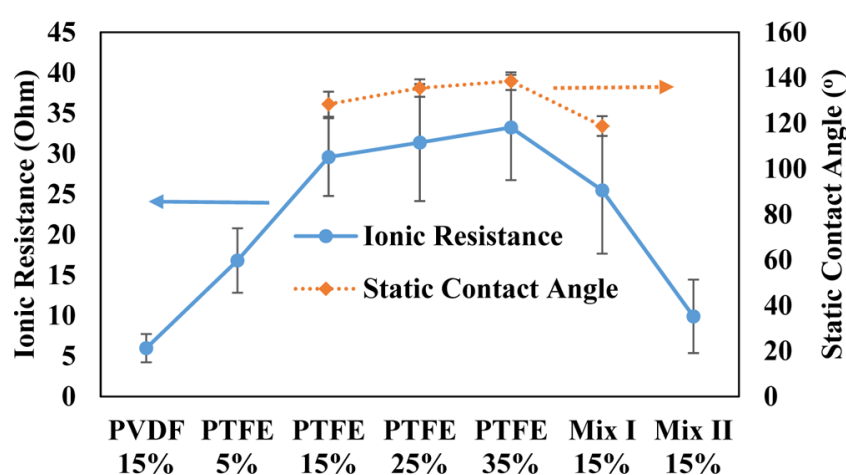

Figure 5. Equivalent ionic resistance of the batteries with customized electrode of different wettabilities.

equivalent resistance measured by electrochemical impedance spectroscopy (EIS) mainly includes the electronic resistance of the electrodes, current collectors, and ionic resistance of the electrolyte, as well as the contact resistance between these components. All electrodes are tested in the same battery frame design with the same electrolyte. Therefore, variations of the equivalent resistance can be attributed to changes of the ionic resistance. More lyophobic electrode impedes the ionic transfer by decreasing the ionic conductivity. The resistance displays the same trend as the static contact angle. In addition, the unstable discharge curves at the end of discharging process imply that lyophobic electrodes still experience $\mathrm{O}_{2}$ starvation on cathode, which increases the overpotential and causes the sudden death of the battery.

To facilitate the oxygen diffusion without significantly sacrificing the ionic conductivity, electrodes with mixed wettability have been designed and tested. The mixed electrode structures shown in Figure $1 \mathrm{c}, \mathrm{d}$ consist of three carbon coatings. In mixed I electrode, the top and bottom layers with $15 \%$ PTFE are lyophobic and the middle layer with 15\% PVDF is lyophilic. The battery with mixed I electrode achieves the highest specific discharge capacity of $5149.5 \mathrm{mAh} / \mathrm{g}$. Because of the lyophobicity of both the top and the bottom coatings, $\mathrm{O}_{2}$ can diffuse into the electrode without much diffusion resistance and reach the electrolyte that accumulates in the lyophilic coating in the middle. This design utilizes the porous structure inside the electrode more effectively. Also, adding a lyophilic layer in the middle of electrode may reduce the $\mathrm{O}_{2}$ diffusion length compared with the fully lyophobic electrode. The combined effects lead to the highest specific capacity. In comparison, the mixed II electrode is composed of one carbon coating with $15 \%$ PTFE layer sandwiched by two carbon coatings with $15 \%$ PVDF. This electrode only results in 2700.6 $\mathrm{mAh} / \mathrm{g}$ deep discharge capacity because the lyophilic top and bottom layers impose more resistance in $\mathrm{O}_{2}$ diffusion. Comparing with the electrode with $15 \%$ PVDF, applying one lyophobic layer in the middle of mixed II electrode increases the discharge capacity by about $1000 \mathrm{mAh} / \mathrm{g}$. The result is consistent with the previous conclusion as well as the study conducted by Xia et al. $^{28}$ that partially wetted electrodes perform better than electrodes fully saturated by the electrolyte. The mixed I customized electrode with stacking coatings (lyophobic coatings on top and bottom with a lyophilic coating in the middle) can be beneficial to promote the design of air electrodes and provide a valuable reference to fabricate highcapacity electrodes.

2.5. Discharge-Charge Cycle. Although this study is focusing on the deep discharge capacity of $\mathrm{Li}-\mathrm{O}_{2}$ batteries with customized electrodes, the cycling performance is also investigated and analyzed. The first discharge-charge cycles of $\mathrm{Li}-\mathrm{O}_{2}$ batteries with customized electrodes at $0.1 \mathrm{~mA} / \mathrm{cm}^{2}$ are shown in Figure 6. The cut-off voltage of charge is set as 4.5 V. The mixed I 15\% electrode as well as PTFE $15 \%$ electrode result in a discharge-charge cycle with the average coulombic efficiency close to $85 \%$, whereas the battery with $15 \%$ PVDF

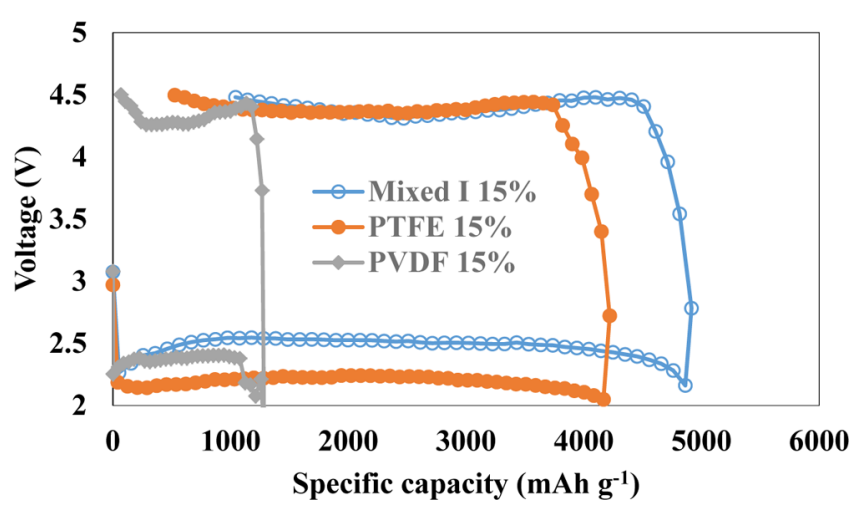

Figure 6. First discharge-charge cycle of $\mathrm{Li}-\mathrm{O}_{2}$ batteries with customized electrode. 
achieves a slightly higher coulombic efficiency of 93\%. The lower coulombic efficiencies of mixed I $15 \%$ electrode and PTFE 15\% electrode can be contributed to the fact that more electrolyte in the lyophobic electrode evaporates because of much longer discharge and charge time, which may increase the ionic resistance during charge and thus deteriorate the coulombic efficiency. ${ }^{29}$ Besides, PVDF favors the thin $\mathrm{Li}_{2} \mathrm{O}_{2}$ film formed on the surface of electrode, whereas PTFE results in more $\mathrm{Li}_{2} \mathrm{O}_{2}$ toroids, which are more difficult to decompose during charging. ${ }^{30}$ The cycling performance of $\mathrm{Li}-\mathrm{O}_{2}$ batteries with PTFE $15 \%$ electrodes is also studied with the cut-off capacity of $1000 \mathrm{mAh} / \mathrm{g}$. Figure 7 shows that coulombic

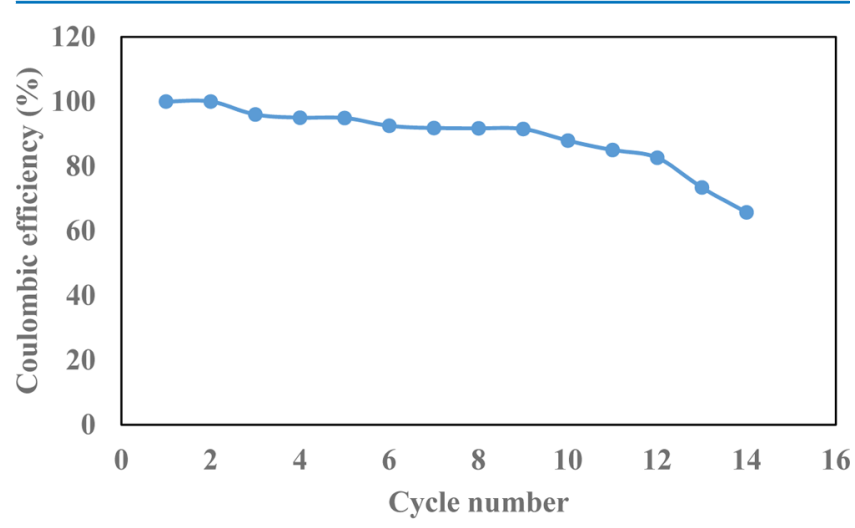

Figure 7. Coulombic efficiencies of $\mathrm{Li}-\mathrm{O}_{2}$ batteries with PTFE $15 \%$ electrode.

efficiency is more than $90 \%$ in the first nine cycles and the discharge-charge curves are shown in Figure S4. The cycling performance of $\mathrm{Li}-\mathrm{O}_{2}$ batteries using customized electrodes is validated. Further study will focus on optimizing the design of customized electrode since the rational structure can increase the cycle life of $\mathrm{Li}-\mathrm{O}_{2}$ batteries. ${ }^{31,32}$

\section{CONCLUSIONS}

The wettability of electrode was mainly altered by mixing acetylene black carbons with PTFE and/or PVDF binders at various weight ratios. The customized electrodes containing PVDF binder or less PTFE binder $(<15 \%)$ were lyophilic, and their corresponding discharge capacities were lower than those of lyophobic electrodes. The electrode with 15\% PTFE exhibited the deep discharge capacity of $4160.8 \mathrm{mAh} / \mathrm{g}$ because lyophobic electrode provided more gas path for $\mathrm{O}_{2}$ diffusion. This study also designed customized electrodes with stacked layers by combining the lyophilic layers with lyophobic layers. The mixed I electrode (15\% PTFE carbon coatings on top and bottom, one $15 \%$ PVDF carbon coating in the middle) showed the highest deep discharge capacity of $5149.5 \mathrm{mAh} / \mathrm{g}$ among all of the experimental cases. The mixed wettability promoted the oxygen diffusion without significantly lowering the ionic conductivity or reducing the number of reaction sites. Therefore, configuring the wettability in the electrode design is an important direction to increase the discharge capacity of $\mathrm{Li}-\mathrm{O}_{2}$ batteries. Further study may focus on improving the configuration of customized electrode wettability considering the spatial distribution of pore size ${ }^{31}$ and specific pore volume of various carbon powders.

\section{EXPERIMENTAL SECTION}

4.1. Electrolyte Preparation. TEGDME (99\%) purchased from Sigma-Aldrich was used as received to prepare the electrolyte. The electrolyte was prepared in a glovebox with $<1$ ppm water and $<5$ ppm oxygen. The electrolyte salt, LiTFSI (99.95\%), from Sigma-Aldrich, was dissolved in TEGDME and the concentration was $1 \mathrm{~mol} / \mathrm{L}$.

4.2. Air Cathode Preparation. AvCarb 1071 HCB plain carbon cloth fabric purchased from Fuel Cell Store was used as the substrate of the customized cathode electrode on cathode. Conductive acetylene black (purchased from MTI Corporation) mixed with various weight ratios of PTFE was dissolved in the ethanol solution to form the carbon slurry. The substrate carbon cloth was dipped into the carbon slurry and dried in the atmosphere for $24 \mathrm{~h}$. Then, the electrode was heat-treated at $350{ }^{\circ} \mathrm{C}$ for $30 \mathrm{~min}$. The electrodes with customized coatings of $5,15,25$, and $35 \%$ (in weight) of PTFE were obtained. In addition, electrodes with 15\% PVDF carbon coatings and electrodes with mixed carbon coatings (both 15\% PTFE and $15 \%$ PVDF) were prepared following the same procedure aforementioned. The schematic views on the structure of the customized electrodes are displayed in Figure 8. The targeted carbon loadings of all customized electrodes were $2 \mathrm{mg} / \mathrm{cm}^{2}$. The measured carbon loadings of the fabricated electrodes were $2.1 \pm 0.1 \mathrm{mg} / \mathrm{cm}^{2}$.

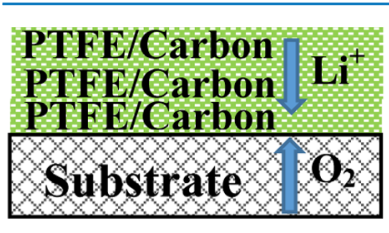

(a)

(c)

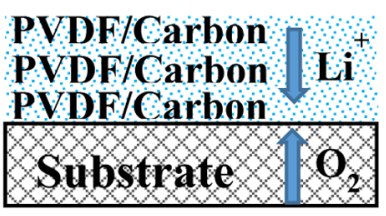

(b)

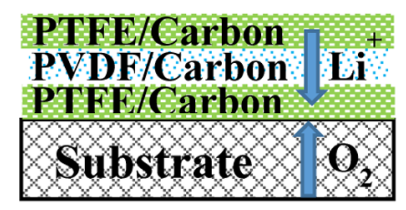

Figure 8. Structural views of customized electrodes with carbon coatings using (a) PTFE binder, (b) PVDF binder, (c) mixed binders I (PTFE + PVDF + PTFE), and (d) mixed binders II (PVDF + PTFE + PVDF) in this study.

4.3. Battery Assembly. The battery was constructed by sandwiching the oxygen diffuser, customized cathode electrode, separator, and lithium chip in the battery frame shown in Figure $9^{29}$ The battery frame was customer-designed and made from highly corrosion-resistant grade 2 titanium. The open ratio of oxygen diffuser was $50 \%$ and the separator was a Whatman GF/ B glass fiber filter from Fisher Scientific with the diameter of 2.1 $\mathrm{cm}$. The lithium chip with the diameter of $1.56 \mathrm{~cm}$ was purchased from MTI Corporation. The PTFE gasket and Oring purchased from McMaster-Carr were inserted to prevent oxygen leaking. All batteries were assembled in the glovebox by adding $60 \mu \mathrm{L}$ of electrolyte in the separator and in the cathode electrode. The substrate layer faced the $\mathrm{O}_{2}$ side and the $1 \mathrm{M}$ LiTFSI/TEGDME electrolyte was added on the coating layer.

4.4. Wettability Measurements. The contact angles between $1 \mathrm{M}$ LiTFSI/TEGDME and surfaces of customized 


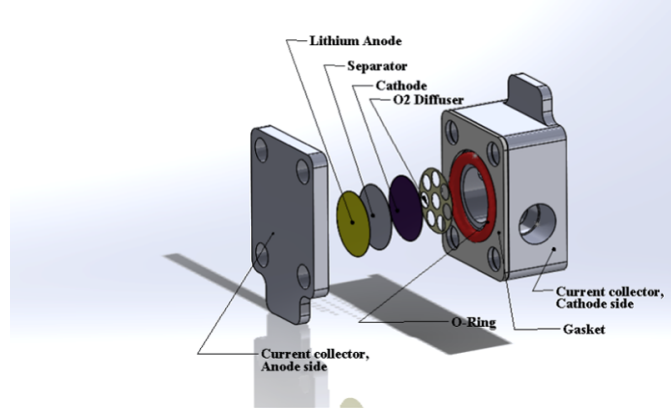

Figure 9. $\mathrm{Li}-\mathrm{O}_{2}$ battery frame and its components. ${ }^{29}$

electrodes were measured using ramé-hart Model 190 contact angle goniometer at the room temperature. The static contact angle, which can be maintained for $120 \mathrm{~s}$ during measurement, was used to characterize the surface wettability. Each measurement was conducted at three different locations on the surface of customized electrodes using $5 \mu \mathrm{L}$ of electrolyte drops. Double-layer capacitance measurement was carried out by the cyclic voltammetry (CV) tests with SP 150 potentiostat from BioLogic Science Instrument. The experimental setup was the same as the battery assembly in the discharge experiment. The $1 \mathrm{M}$ LiTFSI/TEGDME electrolyte was added on the surface of the electrode by a pipette. All CV measurements were performed from -0.2 to $0.2 \mathrm{~V}$ at the scanning rate of 0.2 $\mathrm{V} / \mathrm{s}$ and repeated at least three times. The EIS data were analyzed by the EC Lab software (V11.02).

4.5. Deep Discharge Measurements. Assembled batteries were connected to a four-channel Arbin MSTAT4 battery tester. The pure oxygen was supplied at a flow rate of $0.3 \mathrm{sccm}$, and the pressure of the pure oxygen was maintained at $10 \mathrm{kPa}$ gauge pressure. After resting for $1 \mathrm{~h}$, deep discharge tests were conducted at room temperature and repeated at least three times. ${ }^{18}$ First discharge-charge cycles of $\mathrm{Li}-\mathrm{O}_{2}$ batteries with Mixed I, 15\% PTFE and 15\% PVDF carbon coatings, were also tested and analyzed.

\section{ASSOCIATED CONTENT}

\section{S Supporting Information}

The Supporting Information is available free of charge on the ACS Publications website at DOI: 10.1021/acsomega.8b00808.

Nyquist plots of batteries with customized electrode with different wettabilities, scanning electron microscopy images of customized electrodes with carbon coatings with 15\% PVDF and 15\% PTFE after discharge, the pore size distribution of electrodes, and discharge-charge cycles of $\mathrm{Li}-\mathrm{O}_{2}$ batteries with PTFE $15 \%$ electrodes (PDF)

\section{AUTHOR INFORMATION}

\section{Corresponding Author}

*E-mail: xianglinli@ku.edu. Phone: +1 (785) 8648165.

\section{ORCID}

Xianglin Li: 0000-0002-0193-9410

\section{Notes}

The authors declare no competing financial interest.

\section{ACKNOWLEDGMENTS}

The authors greatly appreciate Dr. Gibum Kwon and his student Mr. Nathan Klein for their assistance on the contact angle measurement using ramé-hart goniometer.

\section{REFERENCES}

(1) Apergis, N.; Payne, J. E. Renewable and non-renewable energy consumption-growth nexus: Evidence from a panel error correction model. Energy Econ. 2012, 34, 733-738.

(2) Abraham, K. M. Prospects and limits of energy storage in batteries. J. Phys. Chem. Lett. 2015, 6, 830-844.

(3) Aurbach, D.; McCloskey, B. D.; Nazar, L. F.; Bruce, P. G. Advances in understanding mechanisms underpinning lithium-air batteries. Nat. Energy 2016, 1, No. 16128.

(4) Zheng, J.; Liang, R.; Hendrickson, M. a; Plichta, E. Theoretical energy density of $\mathrm{Li}$-air batteries. J. Electrochem. Soc. 2008, 155, A432-A437.

(5) Padbury, R.; Zhang, X. Lithium-oxygen batteries-limiting factors that affect performance. J. Power Sources 2011, 196, 44364444.

(6) Girishkumar, G.; McCloskey, B.; Luntz, A.; Swanson, S.; Wilcke, W. Lithium-air battery: promise and challenges. J. Phys. Chem. Lett. 2010, 1, 2193-2203.

(7) Lei, Y.; Lu, J.; Luo, X.; Wu, T.; Du, P.; Zhang, X.; Ren, Y.; Wen, J.; Miller, D. J.; Miller, J. T.; et al. Synthesis of porous carbon supported palladium nanoparticle catalysts by atomic layer deposition: application for rechargeable lithium-O2 battery. Nano Lett. 2013, 13, 4182-4189.

(8) Qin, Y.; Lu, J.; Du, P.; Chen, Z.; Ren, Y.; Wu, T.; Miller, J. T.; Wen, J.; Miller, D. J.; Zhang, Z.; et al. In situ fabrication of porouscarbon-supported $\alpha-\mathrm{MnO}_{2}$ nanorods at room temperature: application for rechargeable Li-O 2 batteries. Energy Environ. Sci. 2013, 6, 519531.

(9) Lu, Y.-C.; Gasteiger, H. A.; Parent, M. C.; Chiloyan, V.; ShaoHorn, Y. The influence of catalysts on discharge and charge voltages of rechargeable Li-oxygen batteries. Electrochem. Solid-State Lett. 2010, 13, A69-A72.

(10) Yang, Y.; Zhang, T.; Wang, X.; Chen, L.; Wu, N.; Liu, W.; Lu, H.; Xiao, L.; Fu, L.; Zhuang, L. Tuning the morphology and crystal structure of $\mathrm{Li} 2 \mathrm{O} 2$ : a graphene model electrode study for $\mathrm{Li}-\mathrm{O} 2$ battery. ACS Appl. Mater. Interfaces 2016, 8, 21350-21357.

(11) Song, H.; Xu, S.; Li, Y.; Dai, J.; Gong, A.; Zhu, M.; Zhu, C.; Chen, C.; Chen, Y.; Yao, Y.; et al. Hierarchically Porous, Ultrathick,"Breathable" Wood-Derived Cathode for Lithium-Oxygen Batteries. Adv. Energy Mater. 2018, 8, No. 1701203.

(12) Beattie, S.; Manolescu, D.; Blair, S. High-capacity lithium-air cathodes. J. Electrochem. Soc. 2009, 156, A44-A47.

(13) Adams, B. D.; Radtke, C.; Black, R.; Trudeau, M. L.; Zaghib, K.; Nazar, L. F. Current density dependence of peroxide formation in the Li-O 2 battery and its effect on charge. Energy Environ. Sci. 2013, 6, $1772-1778$.

(14) Horstmann, B.; Gallant, B.; Mitchell, R.; Bessler, W. G.; ShaoHorn, Y.; Bazant, M. Z. Rate-dependent morphology of Li2O2 growth in $\mathrm{Li}-\mathrm{O} 2$ batteries. J. Phys. Chem. Lett. 2013, 4, 4217-4222.

(15) Li, X.; Huang, J.; Faghri, A. A critical review of macroscopic modeling studies on $\mathrm{Li} \mathrm{O} 2$ and $\mathrm{Li}$-air batteries using organic electrolyte: Challenges and opportunities. J. Power Sources 2016, 332, $420-446$.

(16) Zhang, W.; Shen, Y.; Sun, D.; Huang, Z.; Huang, Y. Objectively Evaluating the Cathode Performance of Lithium-Oxygen Batteries. Adv. Energy Mater. 2017, 7, No. 1602938.

(17) Read, J.; Mutolo, K.; Ervin, M.; Behl, W.; Wolfenstine, J.; Driedger, A.; Foster, D. Oxygen transport properties of organic electrolytes and performance of lithium/oxygen battery. J. Electrochem. Soc. 2003, 150, A1351-A1356.

(18) Mohazabrad, F.; Wang, F.; Li, X. Experimental Studies of Salt Concentration in Electrolyte on the Performance of Li-O2 Batteries at 
Various Current Densities. J. Electrochem. Soc. 2016, 163, A2623A2627.

(19) Schmitz, D.; Anlauf, R.; Rehrmann, P. Effect of air content on the oxygen diffusion coefficient of growing media. Am. J. Plant Sci. 2013, 4, 955-963.

(20) Xu, W.; Xiao, J.; Zhang, J.; Wang, D.; Zhang, J.-G. Optimization of nonaqueous electrolytes for primary lithium/air batteries operated in ambient environment. J. Electrochem. Soc. 2009, 156, A773-A779.

(21) Zhang, Y.; Zhang, H.; Li, J.; Wang, M.; Nie, H.; Zhang, F. The use of mixed carbon materials with improved oxygen transport in a lithium-air battery. J. Power Sources 2013, 240, 390-396.

(22) Chen, M.; Jiang, X.; Yang, H.; Shen, P. K. Performance improvement of air electrode for $\mathrm{Li}$ /air batteries by hydrophobicity adjustment. J. Mater. Chem. A 2015, 3, 11874-11879.

(23) Malmberg, C.; Maryott, A. Dielectric Constant of Water from 00 to 1000 C. J. Res. Natl. Bur. Stand. 1956, 56, 1-8.

(24) Choi, J. W.; Cheruvally, G.; Shin, Y. J.; Ahn, H. J.; Kim, K. W.; Ahn, J. H. Effect of Various Lithium Salts in TEGDME Based Electrolyte for Li/Pyrite Battery. Solid State Phenomena; Trans Tech Publications, 2007; pp 971-974.

(25) Amanchukwu, C. V.; Harding, J. R.; Shao-Horn, Y.; Hammond, P. T. Understanding the chemical stability of polymers for lithium-air batteries. Chem. Mater. 2015, 27, 550-561.

(26) Papp, J. K.; Forster, J. D.; Burke, C. M.; Kim, H. W.; Luntz, A. C.; Shelby, R. M.; Urban, J. J.; McCloskey, B. D. Poly (vinylidene fluoride)(PVDF) Binder Degradation in $\mathrm{Li}-\mathrm{O} 2$ Batteries: A Consideration for the Characterization of Lithium Superoxide. J. Phys. Chem. Lett. 2017, 8, 1169-1174.

(27) Sow, P. K.; Lu, Z.; Talebian, H.; Damron, L.; Mérida, W. Double Layer Capacitance Measurements To Characterize the Water Intrusion into Porous Materials. J. Phys. Chem. C 2016, 120, 2479424802 .

(28) Xia, C.; Bender, C. L.; Bergner, B.; Peppler, K.; Janek, J. An electrolyte partially-wetted cathode improving oxygen diffusion in cathodes of non-aqueous $\mathrm{Li}$-air batteries. Electrochem. Commun. 2013, 26, 93-96.

(29) Mohazabrad, F.; Wang, F.; Li, X. Influence of the Oxygen Electrode Open Ratio and Electrolyte Evaporation on the Performance of Li-O2 Batteries. ACS Appl. Mater. Interfaces 2017, 9, 1545915469 .

(30) Geaney, H.; O’Dwyer, C. Examining the role of electrolyte and binders in determining discharge product morphology and cycling performance of carbon cathodes in Li-O2 batteries. J. Electrochem. Soc. 2016, 163, A43-A49.

(31) Liu, G.; Chen, H.; Xia, L.; Wang, S.; Ding, L.-X.; Li, D.; Xiao, K.; Dai, S.; Wang, H. Hierarchical Mesoporous/Macroporous Perovskite La0. 5Sr0. 5CoO3-x Nanotubes: A Bifunctional Catalyst with Enhanced Activity and Cycle Stability for Rechargeable Lithium Oxygen Batteries. ACS Appl. Mater. Interfaces 2015, 7, 22478-22486.

(32) Liu, G.; Zhang, L.; Wang, S.; Ding, L.-X.; Wang, H. Hierarchical $\mathrm{NiCo}_{2} \mathrm{O}_{4}$ nanosheets on carbon nanofiber films for high energy density and long-life $\mathrm{Li}-\mathrm{O}_{2}$ batteries. J. Mater. Chem. A 2017, 5, $14530-14536$. 